manufacturing industry. While research, development and detailed designing will now, so far as possible, be carried out by parent firms in full cooperation with the Ministry of Supply, the Committee suggests that in the design of instruments of war the responsibility for checking the battle-worthiness of a design and for ordering production to go ahead must always remain entirely with the Government authorities, as well as the responsibility for giving drive and urgency to the creation of a good technical design for a defined purpose. The responsibility for creating such a design, which involves individual qualities of originality and imagination, must on the other hand be handled in close contact with those who have to carry out the task of production.

The measure of responsibility that can properly be delegated to a private firm must largely depend on its character and organization. Normally, the combined responsibility for working out a design and for taking the lead in production as the parent firm of a group should be restricted to firms of stability and proved capacity, with substantial resources and good organization. Moreover, in regard to experience and resources, such close and confidential relations must be reciprocal, and all the technical data and results be placed at the disposal of the Government; there is an implied obligation to work essentially as part of the machinery of Government rather than in the spirit of private concerns. Sometimes the exchange of information and Government assistance appear to be haphazard, particularly when contracts are distributed among a number of firms with no previous experience in the operation of the necessary processes. Certain groups seem to be left without definite leadership, and in other cases where an individual engaged on Government research work may have found means to make contact with manufacturers, the value and extent of his assistance could be greatly increased by strengthening his own staff. The Committee recommends a systematic review of the working of the existing groups, and that the continuance of contact with such groups should be made the responsibility of a special officer or officers.

Scientific workers, while somewhat re-assured by the present report, will undoubtedly await with great interest the result of the further inquiry now proceeding. Reverting to the remark made above that the success of the new arrangements for scientific guidance made by the Minister of Supply (see Nature, September 12, p. 301) depends on the right men being chosen for the key posts, the question of the position of Sir Stafford Cripps naturally arises. With his appointment as Minister of Aireraft Production, he has to bear the responsibilities of the administration of a Department of crucial importance in the struggle. Hence it is scarcely likely that he will be able to devote detailed attention to the activities of the new scientific advisers, and since he is no longer a member of the War Cabinet, he cannot present their views to those who are directing the War. Yet one of the reasons for welcoming the appointment of the three full-time scientific advisers to the Minister of Production was the further statement that they would "work under the immediate supervision of the Lord Privy Seal [Sir Stafford Cripps]" acting on behalf of the Minister. The position is not clear at present, and will be watched by scientific workers and others with keen attention.

\section{CIVIL DEFENCE AGAINST WAR GASES}

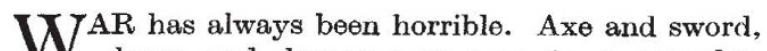
lance and dagger gave way to gunpowder, though it did not entirely displace cold steel even in the Crimean war ; to-day we depend largely on high explosives. During the War of 1914-18 there befell a new horror-chemical warfare, the use of poison gases-which shocked the world. When peace came, the nations solemnly renounced the use of gas at a Geneva conference, a pledge which has so far been kept-nor is there any reason why it should be broken. None the less, the defence against chemical warfare has to be ready. Thus everyone in Great Britain has a gas mask and knows how to use it and care for it. In addition, a highly organized and welltrained gas service has been brought into being, ready to function when required, though hopeful that enough of civilization remains to spare the world this particular horror.

The defence against gas has the advantage over the defence against high explosive or fire bombs that it can be complete. Knowledge of what to do and the ability to do it quickly can make the individual safe in the heaviest gas attack. The value and the efficiency of the general civilian and other official types of respirator cannot be too highly rated. These respirators will stop all the likely war gases and even the strongest concentrations which can be produced in the immediate vicinity of bombs out of doors. They will remain completely effective against lesser concentrations almost indefinitely. It is the duty of men of science to make clear to their lay friends that they can have complete confidence in their respirators.

The other danger to the public is that due to splashes of vesicant gases or prolonged exposure, particularly of the eyes, to vapour from these. The area splashed by any one bomb is small, and in general the number of people likely to be splashed on its bursting will not be large. Should one become a casualty, the skin must be treated without delay with the ointment which has been prescribed for the purpose. In addition, should gas be used, chemists' shops will have pails of bleach cream ready for use by persons who may not have ointment immediately available. The clothing must be shed at once so as to prevent penetration of liquid and vapour to the skin. The Ministry of Health has made ample arrangements both for personal cleansing and for decontamination of elothing. Above all, it is important to keep the eyes shielded should a gas attack be feared. 
The vapour danger from vesicant gases, which exists until the liquid in the streets has been de. stroyed, depends upon the concentration and the time of exposure. This danger is therefore also a function of temperature, which governs the concentration, and so is less at night. Under ordinary conditions the time required to produce blistering effects on the skin may be as much as an hour or more. There is, therefore, no need to run this risk by remaining so long in the vapour. Vesicant burns are highly undesirable wounds, but they can be largely avoided by the exercise of commonsense.

No branch of the national defence has been more fully or precisely documented than gas. The Government has enlisted the help of some of the ablest scientific men of the country to aid the official chemical defence organization in the preparation of a series of A.R.P. handbooks. These were ready from 1936 onwards and have, where necessary, been kept up to date by new editions. The information given in these represents the considered conclusions of many who have thoroughly studied the subject in a practical manner; the handbooks are cheap, and they form the basis of the instruction given to an increasing number of pupils in the A.R.P. training schools. Numerous books on the subject have alsa been published; at the best these are but copies in altered wording of the official handbooks and, where in them an author chooses to air his own views, he runs the risk of being at variance with those who have been in a position to make experiments.

A gas attack may have several consequences: it may injure the individual or contaminate his clothing and surroundings, or it may contaminate foodstuffs, rendering them unfit to eat. This last aspect is a special one, and in view of its importance and the need to prevent any waste of food, it has received full ofticial appreciation and study. The problem involves recognition that a foodstuff may have been con. taminated, a task performed by the Gas Identifica. tion Service; the determination of the degree and extent of the damage by the analyst; and the decision whether the material must be destroyed or can be decontaminated and made fit for consump. tion.

It is necessary and proper to oreate and train an organization ready to cope with gas-contaminated foodstuffs, however great the emergency. There is a tendency, however, in certain quarters to exa. gerate this danger. It is highly unlikely that gases or vapours themselves will harm most foodstuffs, and since the majority of foods are stored inside buildings and are themselves in packages, splashing or liquid contamination is not likely to be a frequent oecurrence. It is arsenical contamination which gives most cause for precautionary measures. It is possible that gas bombs may fall in water reservoirs. Such incidents have to be studied from the point of view of the volume of the reservoir in relation to the volume of the bomb, and may be regarded in general as of small significance in making water unpotable.

It is sometimes overlooked that any gas brought to Great Britain from a foreign country has to be carried in aeroplanes, which are limited in numbers and have a restricted load. Calculations which can readily be made indicate that the maximum possible amount of gas that can be dropped in a given time is very small in relation to the total volume of air over, and total extent of ground-space in, the area attacked. Hence its effect may be expected to be local rather than general, and limited in magnitude. There can be no such thing as a lake of gas persisting over a large area, or a whole city soaked in gas.

To-day the ordinary citizen has a good deal to think about and it may be unfair to expect that, while he regards the use of gas as improbable, he will take a keen interest in his personal defence against gas. There must be no slackening, however, in the effort to train the A.R.P. key men in gas defence, for it cannot be too strongly emphasized that a highly perfected defence against gas is the best means of ensuring that poison gas will not be used against our cities, since such an attack can then have little success. It is obviously impossible to do more than express the view that this work is being well done.

The problems confronting the authorities during and after a raid in any 'target area' are likely to be many and varied. It is to be supposed, for example, that gas bombs will be mixed indiscriminately with high explosive and incendiary bombs. The available resources, growing more scanty as the need for men for the Armed Forces gets more pressing, will have to be deployed to the best advantage, while those in the control rooms will need to be able to appreciate the significance of any happening and to take measures to allay panic and meet the situation. Gas being a weapon, unknown and unseen, may well cause panic unless men with the qualifications of the gas advisers and gas identification officers are available in the control centres and able to reduce the imaginary to the actual danger. The task of such officers is to correlate the mass of evidence from incoming reports, advise in regard to contradictions and anomalies, and generally keep the incident on a sane and sober basis.

The planning of exercises on a large scale is an important part of the training of the senio officers. All the different units concerned learn to know one another and to work together. Such exercises go beyond the actual attack by gas on the people and their homes; they comprise also the rescue of contaminated food, the making safe of streets splashed with mustard gas-an operation which can now be done in relatively few minutes-and the decontamination of the individual room in a house which has received a direct hit.

By such training and preparation, which are part of the normal experience of the Armed Forces, the civil population can be guarded against the effects, subjective as well as objective, of gas attack. Given effective protection, as scientific men will readily appreciate, gas attack can achieve little success; the knowledge that an adequate defence service against gas is in operation will be a major factor in deterring the enemy from using it. 